\title{
Rapid Appraisal of User Stakeholders for Forest Recreation Area Planning: The Little Molas Case
}

\author{
John P. Titre ${ }^{1}$, Allan S. Mills CF ${ }^{2}$, Mark F. Mallaney ${ }^{3}$ \\ ${ }^{1}$ U.S.D.A. Forest Service, Fort Collins, USA \\ ${ }^{2}$ L. Douglas Wilder School of Government and Public Affairs Virginia, \\ Commonwealth University, Richmond, USA \\ ${ }^{3}$ Department of Anthropology, University of Colorado at Boulder, Boulder, USA \\ Email: jtitre@fs.fed.us
}

Received April 15 ${ }^{\text {th }}$, 2012; revised May 19 ${ }^{\text {th }}$, 2012; accepted June $10^{\text {th }}, 2012$

\begin{abstract}
Public forest recreation area planning is often confronted by conflicting stakeholder views of what actions are most appropriate for improving outdoor recreation areas. Contemporary users of an outdoor recreation area are often inadequately represented in these planning decisions, due to the high cost and time required for user surveys that have traditionally been used to represent these stakeholders. A case example of the application of an alternative research method termed rapid appraisal (RA) is described. Data collected using rapid appraisal was used to help resolve disagreements on future planning and development options for the Little Molas Recreation Area (LMRA). The entire RA process was completed in one month's time, with results which provided a reliable stakeholder supplement to working group recommendations to the Forest Service for their proposed LMRA redevelopment plan.
\end{abstract}

Keywords: Recreation Planning; Outdoor Recreation; Forest Recreation; Rapid Appraisal

\section{Introduction}

Rapid Appraisal (RA) integrates several qualitative research methods. It is designed to help empower decision makers through the discovery and understanding of local knowledge from dialog with local populations. The process of RA data collection from forest recreation area users is less costly and time consuming than using standard survey instruments. It employs participant observation and in-depth, context-rich interviews, as well as ancillary information, to small and carefully selected samples of users. The objective is to gather the widest possible understanding of the situation from these data in a relatively short period of time (Carruthers \& Chambers, 1981; Kumar, 1993; Chambers, 1994; Beebe, 1995). Because of reduced budgets for forest planning and management, rapid assessment methods such as this are being used more and more within the fields of forest recreation and natural resources management. RA meets the need for quick and low-cost data collection in today's forest planning environment, while satisfying criteria for sound science to support decisions with data that are reliable, valid, and applicable.

This paper documents the case of a rapid appraisal (RA) study conducted to resolve major disagreements on future planning and development options for the Little Molas Recreation Area (LMRA) on the San Juan National Forest in Southwestern Colorado. It aimed at identifying the activities, perceptions, meanings, values, attitudes, and beliefs that outdoor recreation users had for LMRA. This information was collected in an efficient and timely manner using the rapid appraisal process.

\section{Study Site and User Stakeholders}

The LMRA is situated on Little Molas Lake, at a sub-alpine altitude of just over 10,000 feet. The area is mostly forested, but contains some meadowlands east of the lake. It has a large campground, and all of the campsites, day use, and overnight parking spots within the Little Molas area are free of charge to users. Little Molas Recreation Areas is situated next to the well-traveled Colorado Trail highway, mid-way between the communities of Silverton and Durango, Colorado. A diverse group of stakeholders who are users of this outdoor recreation area exists in these communities. There is year-round recreational use of LMRA, where outdoor activities range from backpacking to snowmobiling.

Little Molas had only one pit toilet, unimproved gravel roads, no designated camping sites with picnic tables, few fire grates, and only minimal signage. As such it provided opportunities for motorized primitive camping. An increase in recreation use from a variety of groups led to resource degradation, including soil erosion and compaction, which alerted managers to the need for some action to prevent continuing harm.

\section{Framing the Issue: Future Desired Conditions for LMRA}

Many of these user stakeholders agreed with the Forest Service that environmental damages, including soil erosion and soil compaction, needed to be remedied. However, beyond this general agreement, the various stakeholder groups have historically disagreed with the Forest Service's proposed plans to slow or stop damages to the resource.

From December 2003 to April 2004 the Forest Service facilitated a collaborative effort in the form of a Working Group (WG), for the purpose of forging a consensus on a plan for LMRA. Public meetings were held in the towns of Silverton and Durango, and the Working Group compiled a report for the Forest Service outlining recommendations resulting from these 
meetings. However, this collaborative process failed to include participants from Little Molas Recreation Area itself, the users of LMRA. As a result of the report, a dilemma emerged between the Forest Service's plan to upgrade LMRA and some stakeholders from these two communities who forwarded various scenarios for making only minor improvements, and who raised the issue of whether or not to implement proposed camping fees.

The Columbine Ranger District had, for some time, been dealing with issues surrounding plans to make modifications to LMRA. The outcry from concerned citizens was the result of an original 2003 Forest Service plan to renovate Little Molas and make various improvements to the campground. This plan included a roadside parking lot, primarily for winter use, a potable water system, and improvements to the access road including gravel and grading. Designated fee campsites were also proposed to replace free and disbursed camping options. Among the concerned citizens who objected to this were members of well organized and vocal constituencies, including the Western Slope No-Fee Coalition and the Backcountry Snow Sports Alliance. However, less vocal individuals and outdoor recreation groups using LMRA were not heard from at this time. Some of them came from other parts of the country (and the world), and some were local backpackers, birdwatchers, picnickers and campers who did not have the time or desire to attend and speak out at formal public meetings.

\section{Rapid Appraisal of Little Molas Users}

A rapid appraisal study was designed to give voice to as many of stakeholders without a voice as possible at Little Molas, and to do so within a short time frame and at low-cost. It was especially designed to capture the viewpoints of those who participated in recreational activities at Little Molas, but who would not come forward during the public comment period for the proposed 2003 plan or participate in a working group.

A common challenge for this type of research is how to combine relevance and rigor. This challenge has been met by recent developments in the methodologies of action research, community based research, and rapid appraisal (RA) within the social sciences (van Willigen, 2002). The RA research approach implemented at LMRA used strategies and procedures originally set forth by applied anthropologist James Beebe in his 1995 article, Basic Concepts and Techniques of Rapid Appraisal. RA at LMRA used Beebe's concepts as a framework for data collection, as well as the writings of many other prominent rapid appraisal methodologists (Belshaw, 1981; Carruthers \& Chambers, 1981; van Willigen, 1991; Chambers, 1994; Utarini, Winkvist et al., 2001; van Willigen, 2002).

RA has become a prominent and efficient mechanism of research in the applied fields of Anthropology and Sociology over the past two decades (Carruthers \& Chambers, 1981; Kumar, 1993; Chambers, 1994; Beebe, 1995). RA differs a great deal from traditional survey research techniques adopted by social science in that it is designed to provide real time information to people on the ground quickly. For the present study "people on the ground" refers to LMRA users as well as Forest Service personnel and other participants in the Working Group.

Following Beebe (1995: p. 42), "rapid appraisal allows a team of two or more individuals, usually representing different academic disciplines, to produce qualitative results for deci- sions about... the design and implementation of applied activities.” For Little Molas, preliminary decisions for the design and implementation of future conditions at Little Molas formed the goal of the study. The purpose was to assist the Columbine District Ranger in making informed decisions about changes for this recreation area.

Three central concepts of the RA methodology help to ensure that the RA research process meets sufficiently rigorous methodological standards: 1) a system perspective; 2) triangulation of data collection; and 3) iteration of data collection and analysis (Beebe 1995). These three aspects of the methodology form a conceptual foundation that allows this research technique to be both flexible and rigorous, thus meeting two key demands of the increasingly volatile postmodern world.

\section{A System Perspective}

A system perspective is defined by elements that logically belong together and make up a whole that has its own qualities and characteristics. "A systems perspective initially considers all aspects of a local situation, but quickly moves toward the definition of a model that focuses on only the most important elements and their relationships to each other" (Beebe, 1995: p. 44). Furthermore, it provides a systems-based means of structuring a debate, rather than a recipe for guaranteed efficient achievement. RA methodology made possible an 'inside view" of the Little Molas Recreation Area, and produced an insight for managers based on place-specific information. The research objective was to understand the aspects of the place that did or did not make it attractive, special, and/or meaningful to the outdoor recreation participants. This network of participants who visit the place, Forest Service personnel involved in planning for the area, and anyone else involved in the situation under examination formed the system for the RA analysis.

This system perspective allows an RA researcher to understand the holistic context of the situation under investigation while narrowing in on the "guts" of the people, places, and management relationships. A research project that involves a system perspective begins by recording as many elements of the system as possible through participant observation and informal conversation. It then quickly moves towards identifying the most important elements of the system relevant to the objectives of the project. In the case of LMRA, those elements were identified as being temporal changes in the place (past, present, and future or desired changes), activity types, use histories, meanings of the place, attraction to the place, fees, and facilities. All of these elements were examined and analyzed according to the larger picture of resource damages and potential change at Little Molas.

\section{Triangulation of Data Collection}

Triangulation is the use of multiple data collection techniques. This helps to ensure reliability of results through the convergence of similar findings from each of the different methods employed. The four qualitative sources of primary data listed below were employed for this study. Through applying a sequential series of data collection methods that included participant observation, semi-structured interviews, key informant interviews, and ancillary working group observations, the soundness of the data could be demonstrated by convergence of the different types of data. 
1) Participant observation;

2) Semi-structured interviews;

3) Key informant interviews;

4) Working group/ancillary observations.

Participant Observation. This was the first qualitative method employed at Little Molas. It requires the researcher to participate in activities with the recreation participants at the study site. To do this, the researchers camped out for two days at LMRA and walked the entire area making behavioral maps to learn about travel patterns and generally becoming familiar with the location. Informal conversations occurred with individuals in the course of observing behavior. The site recreation users viewed the researchers as just other recreationists enjoying the setting. This is the first step in a sequence of escalating depth and detail giving the researchers greater understanding and confidence in reaching deeper into conversations about the issues. The participant observations from Little Molas recreation area were recorded in a project notebook. This same notebook was kept throughout the project and was used for iterations, crosschecking, note taking, and any other recording that was important to the project.

Semi-Structured Interviews. This was the second qualitative method employed at LMRA. For rapid appraisal, 20 to 25 semi-structured interviews are generally conducted with recreation users who are selected to represent the diversity of users present at the study site. Many of the participants in the semi-structured phase were found at campsites where they were actively engaged in cooking, chatting, unpacking, building fires and many other things that you expect to see when entering a campsite. Only one interviewee was interviewed at their campsite. Others were contacted en route to the trails that cut across the campground. All of these folks had driven into the area or had some sort of vehicle with them. The majority of the campers were set up in tents; however a few had hauled in trailers or pop-up tent campers.

Nineteen semi-structured interviews were found to be sufficient at LMRA; saturation being achieved at this point when very little new information was found to be added with each additional interview. Each of the semi-structured interviews was conducted using an interview "guide" created by the research team between the initial phase of participant observation above and the beginning of semi-structured interviewing. The interview guide is not static, like a standard survey questionnaire; it was subject to change and refinement as new information was discovered through the interviewing process. The semi-structured interviews took between four and twenty minutes each, depending upon the length of the dialog.

Key Informant Interviews. This was the third qualitative method employed at LMRA. Key informant interviews were conducted after the initial process of semi-structured interviews had begun. A key informant is someone who is considered knowledgeable relative to the research problem. In the case of LMRA snowball sampling was used in the nearby communities of Silverton and Durango to identify possible key informants. The key informants identified were approached and asked if they were interested in participating in the research process; meeting times and places where then set up for where the key informant interviews were conducted. All but one of the key informant interviews were voice recorded and are on file with the San Juan National Forest. To protect privacy, the names of the key informants were never recorded. Key informants proved to be rich repositories of knowledge. Their responses helped the researchers to confirm the data previously collected using participant observation and semi-structured interviews, while also providing additional new information.

Six key informant interviews were conducted. The group of key informants was comprised of a backcountry dog sled and snow skiing guide, a hardware store owner and member of the Silverton planning commission, the owner of a horseback outfitter, a mountain bike store and motorcycle shop owner, a small jewelry store owner with a heavy interest in cross country skiing, and the manager of the Durangelers fly fishing shop who has fished at the lake for years. These interviews were conducted in a variety of settings from a coffee shop and a restaurant to the homes and stores of the participants. Most key informant interviews lasted about thirty minutes and most closely resembled friendly conversations.

Throughout the course of data collection for this project we rigorously searched out diverse people to speak with. These participants ranged in age from 23 to 78 years old, were equal in their representation of males to females, and held various occupations from students and registered nurses to retirees and small business owners. A combined total of 25 people participated in both the semi-structured and key informant interview processes and their recreation interests at Little Molas were wide in scope. Their recreation activities included camping, day hiking, enjoying nature, bait fishing, mountain biking, horseback riding, backpacking, birding, picnicking, four wheeling, mountaineering, snowmobiling, cross country skiing, dog sledding, fly fishing, snowshoeing, mushroom gathering, mineral hunting, and star gazing. This wide range of outdoor activities in which the participants took part covers most of the major types of use at Little Molas Recreation Area.

Working Group Observations. This was the fourth and final source of qualitative data. A working group collaborative process took place over several months at meetings that lasted around two hours each. There were four meetings of the working group between January and March 2004. All working group information was obtained from a Forest Service employee who helped in administrating the process. Notes from each meeting, including the town meetings at Durango and Silverton, vote counts, and the final report were included in this data set. All documents from the working were kept together in a file and treated as though they were interview transcripts. Researchers used the working group as a sort of think tank to gain feedback about possible actions and adjustments that may come about as a result of the study. The working group participants made recommendations, but they also provided review of the information collected through semi-structured and key informant interviews.

Some related data were also collected for the RA research effort from secondary sources. These included the Durango Herald, the Silverton City Archives, and online sources. All of this information was kept on file and used to build a perspective of the situation, events, and major players at Little Molas over time.

Employing all of these essential qualitative methods results in triangulation of findings, where convergence of similar information from different methods of data collection provides confidence in the reliability of the findings. Interpretation of reliable results can then be used by planners and managers to make informed decisions in places where the wrong choice could lead to a lawsuit and the loss of substantial amounts of time and money. 


\section{Iteration of Data Collection}

Iteration refers to frequent pauses in data collection that allow the researchers to discuss and analyze information in order to ensure that study objectives are being met, and to sometimes generate new research questions. The small sample size in RA makes it imperative that those involved in data collection continually review the content and substance of the interviews by stopping frequently to interpret data (Beebe, 1995). During these pauses, the team of investigators creates matrices outlining typologies of participants. These matrices insure that the study is contacting diverse groups of people who have different interests in the place under examination. Iteration further allows researchers to continually analyze and discuss what has been learned from the dialog throughout the RA process.

After seven of the 19 Little Molas semi-structured interviews had been conducted at Little Molas, the researchers created an iteration matrix to reflect on the data. The iteration matrix consisted of representative lists identifying the key characteristics of participants. This information was coupled with participant observations during the next iteration allowing the researcher to seek out different types of participants who had been previously missed. This crosschecking methodology helped the study gain depth and validity by providing purposeful diversity within the data pool (Chambers, 1994; Beebe, 1995). Semi-structured interviews from Little Molas Lake were recorded in iteration phases. In the first phase, interviews 1-7 were written out by hand in the project notebook. In the next phase, interviews 8-19 were recorded on an Olympus ${ }^{\mathrm{TM}}$ DS-330 Digital Voice Recorder and then transcribed into the notebook. All semi-structured interviews and iteration matrices were converted into a digital text document for analysis. Key informant interviews were also recorded on the Digital Voice Recorder, but were not transcribed into a notebook or a digital document.

\section{Bracketing and Interpretation of the Data}

After data collection, the RA process at Little Molas moved on to an analysis phase known as bracketing and interpretation. Bracketing refers to the identification, classification, and grouping of emergent themes that were interpreted using an hermeneutic technique for analysis (Guba, 1989). This hermeneutic, or meaning making, process brings yet another element of rigor into the RA research project. Cyclical processes of analysis and review form the principle mechanism of a hermeneutic method for interpretation. In our process this was employed after all of the interview transcripts had been created and printed out in one volume.

First, the researchers read through the transcripts many times to become familiar with the content and to reflect on the context of the interviews. After these careful and close readings were completed the text was divided up into complete thoughts or "meaning units" (Patterson and Williams 2004 unpublished). Each meaning unit was then classified into a subject bracket that allowed going deeper into the information for each guided objective. The final subject brackets analyzed and interpreted were temporal changes (past, present, and future or desired), activity types, use histories, meanings, attractions, fees, and facilities (often times very similar to the temporal change bracket).

These meaning units, once placed within their subject brackets, were analyzed for contextual meaning and marked with themes. Thus, for each subject bracket we were able to designate the emergent themes from the three interview processes and the working group information. Each of these interpretations and themes were then illustrated in the construction section which followed. By exposing the narratives and their themes, it was possible to gain perspectives into Little Molas Recreation Area from the viewpoints of the RA study participants and what they desire for LMRA in the future. These results were then cross-checked this with the information from the Forest Service working group/ancillary observations. Support for some of the working group recommendations emerged from these other data sources, giving voice to many more stakeholders than would have been possible with the working group collaborative process alone.

\section{Limitations of the Research}

Because RA deals with a relatively low number of participants it is likely that those interviews comprising the RA samples will not be wholly representative of all the LMRA user stakeholders. This becomes less important when it is understood that the RA process is purposive in that it looks for diversity over time within the interview pool. It is admittedly difficult to say when and if you have covered all of the bases (so to speak) with an RA study, however it is possible to identify obvious cut-off points (saturation) in data collection. The rigor and purposive nature of the interviewing techniques leads to a fair and reliable understanding of the trends in perceptions, values, attitudes, and beliefs that are so important to outdoor recreation area planning.

Another important limitation of RA could be the short time period in which it is conducted. On one hand, the rapid completion of the Little Molas study in four weeks time made it inexpensive. However, the RA data collection was conducted during the month of August, when tourism was at its peak. Thus, a traditional survey researcher used to drawing representative random samples might conclude that results of this RA study pertain only to August. In response, the authors feel that, due to the nature of the purposive sampling used in rapid appriasal, RA studies conducted at other times during the year and using the same sampling techniques and triangulations would likely result in similar conclusions, themes, and emergent narratives.

\section{Study Results}

Results showed that most semi-structured interview participants who were contacted within the Little Molas campground were there to get away from the towns where they live and to have a nice outdoor experience, often with friends or family. Through participant observation, it appeared as though the LMRA participants were generally content and happy with their surroundings and many of them expressed feelings of happiness directly attributed to the area. The researchers were never refused an interview and each of the interviewees was kind and seemed interested in the process.

\section{Constructed Accounts of Little Molas Lake}

Results of the semi-structured interviews are presented as "constructed accounts" of LMRA. These accounts demonstrate when a particular developmental recommendation from the working groups should be viewed as supported, or otherwise. 


\section{Diversity of LMRA Activities Participation}

Results of semi-structured interviewing demonstrate that Little Molas offers a wide range of opportunities for recreational activities. Many of these activities were associated with Little Molas Lake. Interviewees was asked to discuss their primary activities, as well as those activities in which they would participate on a 'typical' day there. Their "primary" activities, in order of how often they were mentioned, were: Camping, hiking, enjoying nature, fishing, mountain biking, horseback riding, birding, relaxing, and eating. Their "routine" activities were, in order: hiking, fishing, eating, relaxing, camping, observing nature, mountaineering, biking, four wheeling, and horseback riding. Both the lists of primary and routine activities are evidence of diversity in activities participation at Little Molas.

\section{Place Attachment}

The semi-structured interview participants evidenced varying levels of Little Molas use over time. Six of the nineteen semi-structured interviewees were making their first visit to the area, while thirteen of them were returning. One 39-year-old male respondent from California had never been to Colorado before his visit to Little Molas Lake, and he found out about it by speaking with locals in Durango. He mentioned that the place was special to him because it marks the first spot where he camped in the Rocky Mountains, which had moved him with the vistas and beautiful scenery. This gentleman was traveling with his extended family members visiting from Mexico. He compared the area to some spots in Washington State and the high country of Yosemite National Park, but pointed out that he had to pay at those areas and he liked the fact that there was no fee at LMRA saying, "leave it just as it is.” He also told us that he "wouldn't mind paying 5, 10, or even 15 dollars" to stay at Little Molas but that "when you pay to camp somewhere you tend to be less respectful of the area because it's almost like they are lending the land to you, here (LMRA) you have to take care of it more."

\section{Willingness to Pay Fees}

Only three of the 19 semi-structured interview participants said that they would return to the area if a fee were collected for camping or day use. Three others said that they might "be ok" with fees. Eight other people who responded to this question said that they were totally opposed to fees and that they should not be imposed at Little Molas Recreation Area. One 45 yearold woman from Bayfield, Colorado said that she had "really mixed feelings about fees, um, I'm a heavy user of recreational areas and I do know that it takes money to maintain them so I don't totally object to fees. I would want to know that they were being used in a way to leave things be rather than sort of building it up more.” This was a very common sentiment with the participants. Another 52-year-old woman from Durango said that she would be "perfectly willing to pay a fee and if we were paying a fee they should use it to keep areas like this more like this, as opposed to putting in major roads, and even just to buy more land.” This is a simple theme on fee use that is repeated over and over again in the transcripts from the semistructured interviews. While a few were philosophically opposed to fees on public lands, the vast majority of the folks simply fear fees because they are perceived to come hand in hand with facilities and development.

The people at Little Molas come to get away from the or- ganization of their everyday lives, saying things like "it's natural. That's the reason I come up here. I don't like established campgrounds.” One 41-year-old mother from Durango said that "if they made it into a campground where everybody had their units" it would ruin her experience there. She followed up this statement with that very same theme of fees and development saying, "I don't have a problem paying a little bit of a fee or something, but still I just don’t (like established campgrounds). That's how I grew up and I come up here to get away from people.” Another lifelong Durango resident put it more simply by saying, "This is my home, and I won't pay to camp in my home."

\section{Non-Development Preferences}

The most common responses to questions about desired changes in the area also indicated a theme of non-development. One 58-year-old man from Sioux Falls, South Dakota replied, "The nice thing is that it stays pretty much the same." He also told the interviewers not to "pave the road. Keeping it in a natural state is really important to us. Of course, we live in a motor home. If we want a motor home park we can go find it. Don't let this develop into some kind of commercial area.” It was clear that participants did not want Little Molas to become a developed recreation area. The things people named as attractive elements for LMRA further support the theme of preserving the natural character of the place. These named attraction factors sorted into three categories. The first category has to do with natural factors that attract people to the area. The second category relates to the man-made aspects of LMRA, such as roads and facilities. The third category is for responses that include both natural and man-made factors. It is interesting that, in most cases, people were attracted to Little Molas because of the natural factors. When their attraction to the area was related to humans it was almost always pertaining to the lack of people and their influences on the natural character of the area. With respect to man-made attractions, a gentleman from South Dakota said that for him the Colorado trail was the main attraction. Another 40-year-old man from West Virginia commented on the "nice, clean facilities." Responses that fall into the natural category were most commonly relating to the beauty of the area and the scenery; others mentioned the fresh air and the quiet solitude. Responses that fell into the category of both natural and human elements commented on the beauty as well as the lack of people. Others mentioned natural beauty and the fact that there was no fee as attractive.

\section{Facilities Preferences}

Seven of the 19 participants were in favor of upgrading the restroom facilities, two would like to see the road improved, and nine people thought that the current facilities were sufficient for the campground. There were no responses calling for major overhauls of the facilities. A woman from Bayfield said, "Well, I know that there've been plans to kind of do more, um; Building up the campgrounds and stuff like that would definitely spoil it for me.” In light of some of the resource damage at the area, people generally desire a fix that is less visible and does not promote increased use at Little Molas. A woman from Durango remarked, "I had read that there were places where they were concerned about erosion and it might be good if they made it real obvious, places where you shouldn't drive and shouldn't park and stuff." Going on she said that she would 
recommend the use of natural barriers, like logs or big rocks, to achieve this end.

\section{Key Informant Interview Consistency Check}

The key-informant interviews allowed for construction of a consistency check with the above results from transcripts of the semi-structured interviews. Key-informant interviews produced evidence of diversity in activities participation. One or more key informants participated in: backcountry skiing, dog sledding, snowmobile riding, backpacking, fly fishing, horseback riding, mountain biking, motorcycling, camping, mushrooming, wildlife viewing, day hiking and exploring, photography, wildflower viewing, hunting, and trail running. The key informants were very knowledgeable about the area and use it frequently, thus their responses to similar prompts will either show reliability of the information through consistencies, or they will rebuke the findings of the semi-structured interviews.

Of the six key informants involved in the research, one was in favor of development at Little Molas Lake as a form of mitigation. "At a place like Little Molas it used to be an accomplishment to get there, you know? The road wasn't that good, Our pickups weren't that good, Our snowmobiles weren't that good. If we could even get there we thought, 'Yeah! We did pretty good'. Now we can go farther. We push the envelope and at a place like Little Molas we need to set the artificial boundaries more aggressively to say this is where you park and this is where you camp instead of saying well, go have a good time." To this older gentleman, protection of the riparian zone was his central theme. "Ruts in the riparian zone or trash in the creek would spoil it. The area around the water is kind of sacred.” He would like to see camping kept out of the riparian zone and some signage to put social pressure on people who don't follow the rules.

Two other informants, one male and one female, were attracted to the area by the great winter skiing opportunities and the Colorado trail in the summer. Their comments were consistent with the willingness-to-paytheme which was detected with semi-structured interviews. These two were completely opposed to fees, but also felt that fixing erosion damage was crucial. The woman said, "I think that if you start charging fees it changes everything. A lot of people get into hiking and backpacking because once you have all the gear it's something that you can do for free." She went on to say that, "To curb erosion it could just be like a park and walk-in type of camping. So people park somewhere designated and then and then walk a little way to the camp... if that's a big deal then you can just go pay \$16 (at a developed campground) across the street at Molas." One man was quoted as saying, "Well, there are plenty of opportunities in the area for people who want that RV or big trailer camping. I think it's important to keep Little Molas Lake like it is, because it's not taking that experience away from people because there's other opportunities close to Little Molas.”

Once again, we saw the non-development theme of Little Molas as a natural area that needs to be protected from both erosion and emerging development detected within the semistuctured interviews, as also very apparent among these key informants.. Another man, a fly fisherman from Durango said, "it should stay primitive. Right across the street you can go to Big Molas and hook your RV up and do it all. Clean up the lake but don't change a thing otherwise.” He cited erosion problems as the cause of lake damages. "It used to be a deep lake 25 years ago all the way around. Now you've got sediment flow that's diminishing the amount of water and biomass.” His comments also showed consistency with the call for bathroom improvements, detected in some of the structured interviews, as a desired change. "I think the bathroom could be enhanced because of the use it gets in the summer. One of the better ventilated ones... that would be something that I would not be opposed to.” However, his main point was "trying to pin-point erosion and making attempts to stabilize it."

A woman with tribal roots from Silverton had discovered the area in the 1970s hiking and exploring. She said, "The wonderful thing is that it's so natural and beautiful. The accessibility is great. You can get the wilderness experience without going too far or paying.” This comment again shows an element of consistency (and saturation) with the place attachment semi-structured results. She recommended limiting the numbers of campsites to avoid overuse problems that she has witnessed around the lake. She also said, "I think the toilet facilities are really important to maintain, and even improve, in order to keep the area clean.” She told the interviewers, "This is my life, this is really important to me. What's nice there is that you can really get to a nice natural place. In the tribe that I'm from our church is a lake on top of a mountain, and you find that out there. Most people here are happy to share the area with people from the cities, but often times they need to be educated about the impact they have."

\section{Conclusion}

There were some obvious thematic consistencies in the data from both semi-structured and key-informant interview sets. In general, both of those data sets demonstrated that people promote ideas that will protect the area from future damages. All participants shared the desire to maintain the natural character of LMRA. One related theme was the perception of unchecked development as damaging. Every participant at the Little Molas recreation area saw a need to fix erosion and stop the driving of motorized vehicles beyond designated roads. The most common recommendations for solving this problem called for designated parking areas, and natural roadblocks to keep people within acceptable use zones. A call for upgraded restroom facilities was another common theme. Two other common themes were keeping the area free of fees and free of excess fire ring control. The comparison of constructions from the semi-structured process and from the key informants shows the theme of protection without excessive development. In general, it can be concluded that further development is perceived to be potentially just as destructive as current resource damages. Only a small minority of users would like to the see the area turned into a more developed camping area. This indicates that, from the point of view of LMRA users, that planning option should be dropped, especially since the option of developed camping is available at another campground nearby. The recommended course of action is to keep the Little Molas recreation area primitive, while attempting to solve resource damage problems with the least visible impacts.

The recommendations of the working group were similar to the recommendations that emerged from the two interview processes. Both groups of interview participants felt similarly to the working group about the issues at Little Molas recreation area on a number of recommendations. The recommendations 
of the working group showed evidence of consistency with the desires of the semi-structured and key-informant participants in the RA process. The working group proposed rehabilitating the damaged resources. They proposed keeping the existing undeveloped and natural character of Little Molas, to accommodate a variety of users interested in a less developed recreational experience, and to keep Little Molas a non-fee camping area. All of these themes were emergent from the narratives of both the semi-structured interviews and the key informant interviews. These consistencies found through triangulation of data collection methods are evidence that these opinions and desires represent the majority of user stakeholders who both value and recreate at Little Molas. Results from all of the triangulated RA data collection methods pointed toward a course of action that can be followed and implemented easily and economically by the Forest Service. The central lesson learned from the stakeholders is that no one wants to see the Little Molas recreation area destroyed; not by careless campers causing unchecked erosion and resource damage or by management through development.

\section{REFERENCES}

Beebe, J. (1995). Basic concepts and techniques of rapid appraisal. Human Organization, 54, 42-51.

Belshaw, D. (1981). A theoretical framework for data-economizing appraisal procedures, with applications to rural development planning. Bulletin, 2, 12-22.

Food and Agriculture Organization of the United Nations (1989). Community forestry: Rapid appraisal of tree and land tenure. Rome: Food and Agriculture Organization of the United Nations.

Carruthers, I., \& R. Chambers (1981). Rapid appraisal for rural development. Agricultural Administration, 8, 407-422. doi:10.1016/0309-586X(81)90036-4
Chambers, R. (1994). The origins and practice of participatory rural appraisal. World Development, 22, 953-969. doi:10.1016/0305-750X(94)90141-4

Costello, P. J. M. (2003). Action research. London: Continuum.

Guba, E. G., \& Lincoln, Y. S. (1989). Fourth generation evaluation. Newbury Park, CA: Sage.

Jason, L. (2004). Participatory community research: Theories and methods in action. Washington, DC: American Psychological Association. doi:10.1037/10726-000

Kumar, K. (1993). Rapid appraisal methods. Washington DC: World Bank.

National Research Counsel (NRC) (1986). The special problem of $\mathrm{cu}$ mulative effects. Ecological knowledge and problem solving: Concepts are case studies. Washington DC: National Academy Press.

Patterson, M. E., \& Williams, D. R. (2004). An Interpretive paradigm for collecting and analyzing data: Principles, methods, and case examples. Unpublished Report, 12-49.

Stringer, E. T. (1999). Action research. Thousand Oaks, CA: Sage Publications.

USDA Forest Service (2003). Model of a forest plan. Volume 1, November 2003. Ft. Collins, CO: USDA.

USDA Forest Service (2003). Building a forest plan. Volume 2, November 2003. Ft. Collins, CO: USDA.

USDA Forest Service (2003). The adaptive planning process. Volume 3, March 2003. Ft. Collins, CO: USDA.

Utarini, A. et al. (2001). Appraising studies in health using Rapid Assessment Procedures (RAP): Eleven critical criteria. Human Organization, 60, 390-400.

van Willigen, J. (2002). Applied anthropology an introduction. Westport, CT: Bergin \& Garvey.

van Willigen, J., \& Finan, T. L. (Eds.) (1991). Soundings: Rapid and reliable research methods for practicing anthropologists. Arlington, VA: American Anthropological Association.

Wilkins, L., Swatman, P., \& Castelman, T. (2004). Faster, Richer, better: Rapid appraisal techniques for the study of IS implementation in virtual communities. The Qualitative Report, 9, 161-175. 